\title{
Comparison among bone marrow mesenchymal stem and mononuclear cells to promote functional recovery after spinal cord injury in rabbits ${ }^{1}$
}

Antônio Filipe Braga Fonseca', Jussara Peters Scheffer", Arthur Giraldi-Guimarães"', Bárbara Paula Coelho $^{\mathrm{IV}}$, Raphael Mansur Medinav ${ }^{\mathrm{v}}$ André Lacerda Abreu Oliveiravı

'PhD in Sciences, Laboratory of Animal Health, Center for Agricultural Sciences and Technologies, Animal Experimentation Unit, Universidade Estadual do Norte Fluminense Darcy Ribeiro (UENF), Campos dos Goytacazes-RJ, Brazil. Intellectual, scientific, conception and design of the study; technical procedures; aquisition and analysis of data; manuscript writing. "Fellow PhD degree, Laboratory of Animal Health, Center for Agricultural Sciences and Technologies, Animal Experimentation Unit, UENF, Campos dos Goytacazes-RJ, Brazil. Conception and design of the estudy, technical procedures, critical revision.

I'PhD in Sciences, Associate Professor, Laboratory of Cell and Tissue Biology, Center for Biosciences and Biotechnology, UENF, Campos dos Goytacazes-RJ, Brazil. Analysis and interpretation of data.

IVPhD in Sciences, Laboratory of Cell and Tissue Biology, Center for Biosciences and Biotechnology, UENF, Campos dos Goytacazes-RJ, Brazil. Acquisition of data.

'PhD in Sciences, Laboratory of Animal Health; Center for Agricultural Sciences and Technologies, Animal Experimentation Unit, UENF, Campos dos Goytacazes-RJ, Brazil. Acquisition of data.

VIPhD in Sciences, Associate Professor, Laboratory of Animal Health; Center for Agricultural Sciences and Technologies, Animal Experimentation Unit, UENF, Campos dos Goytacazes-RJ, Brazil. Critical revision, final approval the manuscript.

\section{Abstract}

Purpose: To investigate the efficacy of allogeneic mesenchymal stem-cells and autologous mononuclear cells to promote sensorimotor recovery and tissue rescue.

Methods: Female rabbits were submitted to the epidural balloon inflation method and the intravenous cells administrations were made after 8 hours or seven days after injury induction. Sensorimotor evaluation of the hindlimbs was performed, and the euthanasia was made thirty days after the treatment. Spinal cords were stained with hematoxylin and eosin. Results: Both therapies given 8 hours after the injury promoted the sensorimotor recovery after a week. Only the group treated after a week with mononuclear cells showed no significant recovery at post-injury day 14. In the days 21 and 28, all treatments promoted significant recovery. Histopathological analysis showed no difference among the experimental groups. Our results showed that both bone marrow-derived cell types promoted significant sensorimotor recovery after injury, and the treatment made at least a week after injury is efficient.

Conclusion: The possibilities of therapy with bone marrow-derived cells are large, increasing the therapeutic arsenal for the treatment of spinal cord injury.

Key words: Transplantation, Homologous. Transplantation, Autologous. Bone Marrow Cells. Rabitts. 


\section{Introduction}

Lesions in the Central Nervous System (CNS) represent the major causes of disability worldwide, having catastrophic effect in the daily lives of those affected and their families. Moreover, it represents a high financial burden for the families and for the health care systems of countries ${ }^{1,2}$. For these reasons, scientific community has made a large effort to discover new and effective approaches to treat these conditions, aiming to promote increased nervous tissue protection, regeneration and neurologic recovery ${ }^{3,4}$. One of the most incident and prevalent forms of CNS lesion is the spinal cord injury $(\mathrm{SCl})$, which causes motor, sensory and autonomic dysfunction ${ }^{1,5}$.

One of the promising approaches to treat the $\mathrm{SCl}$ is the cell therapy, in especial the use of bone marrow-derived cells ${ }^{7,8}$. Many previous works have described the beneficial effects of the treatment with bone marrowderived mesenchymal stem cells (MSC) in animal models of CNS lesions ${ }^{8,9}$. Moreover, the feasibility and safety of a therapy for $\mathrm{SCl}$ with MSC in humans has been already examined in clinical studies ${ }^{6}$. MSC have good potential to promote nervous system repair, mainly because of its ability to migrate to damaged tissues and to release several soluble molecules with a wide range of protective and regenerative action $^{10}$. However, its utilization requires cell cultivation for several weeks, increasing the risk of contamination and turning the autologous treatment unfeasible in the acute phase of the post-injury process (unless the patient has a culture of its own MSC made before the injury). Several reports have demonstrated that the MSC are hypoimmunogenic, and actually the allogeneic transplantation of these cells has been shown to be as effective as the autologous one ${ }^{11-13}$. Thus, the treatment of $\mathrm{SCl}$ in the acute stage could be done by allogeneic transplantation of MSC.
A protocol alternative to the use of the MSC is the use of the bone marrow mononuclear cells (BMMC). These cells can be harvested from the bone, separated and prepared for transplantation in a few hours (hr), avoiding the need for cultivation. BMMC are composed by hematopoietic progenitor and differentiated cells, endothelial progenitor cells, MSC and hematopoietic stem cells ${ }^{14}$. MSC are estimated in $0.001-0.01 \%$ of the total bone marrow nucleated cells ${ }^{15}$. Since the BMMC have many differentiated cell types, its transplantation is recommended to be autologous, or at least between animals of the same lineage, to avoid immunologic response and rejection. BMMC have been described as able to be chemoattracted to lesioned tissues and capable to release many cytokines and trophic factors ${ }^{16}$. Indeed, several studies have shown the efficacy of the BMMC to treat CNS lesions ${ }^{17-20}$, and clinical studies about the treatment of the $\mathrm{SCl}$ with autologous $\mathrm{BMMC}$ are in progress ${ }^{21,22}$. There are few comparative studies which suggest that MSCs and BMMCs have very similar potential to promote nervous system rescue and functional recovery ${ }^{23,24}$.

An important parameter for the efficiency of a cell therapy is its therapeutic time window after the injury. Studies with models of brain ischemia have suggested that the MSC are effective to promote recovery when administrated until a month after the injury ${ }^{25,26}$. However, the BMMC seem to have a smaller window to be effective ${ }^{11,27}$. From our knowledge, the therapeutic time window for the bone marrow-derived cells has not been consistently evaluated in models of $\mathrm{SCl}$.

In the present study, using the model of $\mathrm{SCl}$ by balloon compression in rabbits, the aim was to compare the effectiveness of allogeneic MSC and autologous BMMC to promote sensorimotor recovery and tissue rescue. Furthermore, we evaluated their effectiveness in two time windows of administration after 
the $\mathrm{SCl}$, one very short and clinically unlikely, and other larger but clinically feasible.

\section{- Methods}

Our experiments were carried out in accordance with the National Institute of Health Guide for the Care and Use of Laboratory Animals, and were approved by the Animal Ethics Committee of our institution (CEUAUENF, protocol \# 179, accepted in 18/12/2012).

Female New Zealand albino rabbits weighing 2.5 to $3 \mathrm{~kg}$ were used in this study. All animals were housed in a colony room with food and water available ad libitum.

\section{Surgery}

The $\mathrm{SCl}$ was induced by the model of the epidural balloon inflation, a method that is considered simple and reproducible ${ }^{28,29}$. After induction of anesthesia with midazolam maleate (3 $\mathrm{mg} / \mathrm{kg}$ ) associated with the ketamine hydrochloride $(25 \mathrm{mg} / \mathrm{kg})$, administered intramuscularly, a trichotomy of the thoracolumbar region was held. The intraoperative fluid management was performed with Ringer's solution added with lactate through the marginal vein of the left ear. The anesthetic maintenance was conducted by the vaporization of isoflurane in $100 \%$ oxygen at $2 \mathrm{l} / \mathrm{min}$. Cardiac and breathing parameters were monitored throughout the surgical procedure. The animals were placed in the ventral decubitus position to allow good visualization of the spinal canal. A dorsal laminectomy was made to allow the introduction of the catheter. The dorsal spinous processes, blades and pedicle portions of the L3 vertebra were carefully removed to expose the dorsal surface of the spinal cord and nerve roots. Then, a 4F Fogarty catheter (Edwards ${ }^{\circ}$ ) (Figure 1) was slowly and dorsally inserted inside the spinal canal until the tip was located around the place of the T13 vertebra. The balloon located on the tip of the catheter was inflated using $1 \mathrm{~cm}^{3}$ of air (Figure 1), and remained inflated for $10 \mathrm{~min}$ to promote the $\mathrm{SCl}$. After this time, the balloon was emptied and slowly removed from the spinal canal, and the access site was closed. All animals received antimicrobial therapy with the intramuscular administration of enrofloxacin $(5 \mathrm{mg} / \mathrm{kg}$ ) during 7 days, and morphine hydrochloride as analgesic ( $1 \mathrm{mg} / \mathrm{kg}$ ), every $8 \mathrm{hr}$, during 4 days.
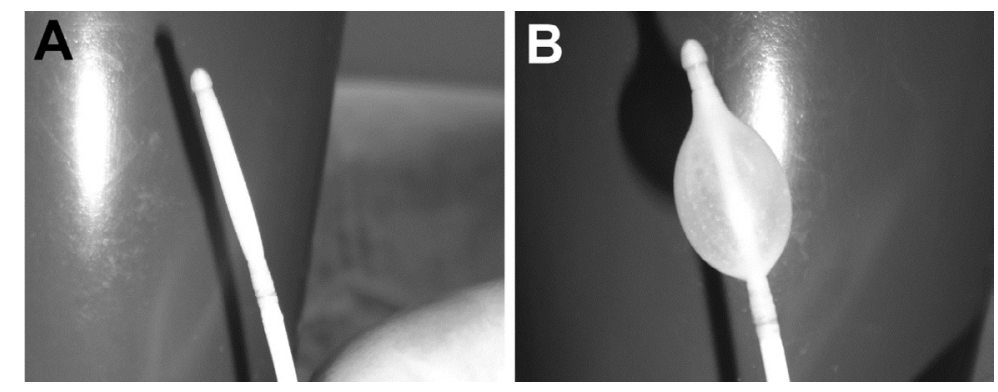

Figure 1 - Photographs showing the tip of the catheter with the inflatable balloon empty (A) and full (B).

Before the beginning of the experiment, the surgical procedure was trained using some non-experimental animals. Computed tomographic (CT) images were obtained using a GE LightSpeed Multi-slice 32 channels CT scanner, to confirm the correct placement of the balloon inside the T13 vertebra and the level of filling of the balloon inside the spinal canal (Figure 2). The length of the catheter that had to be inserted from the L3 vertebra to reach the place of the T13 vertebra was established and repeated in all experimental animals. 

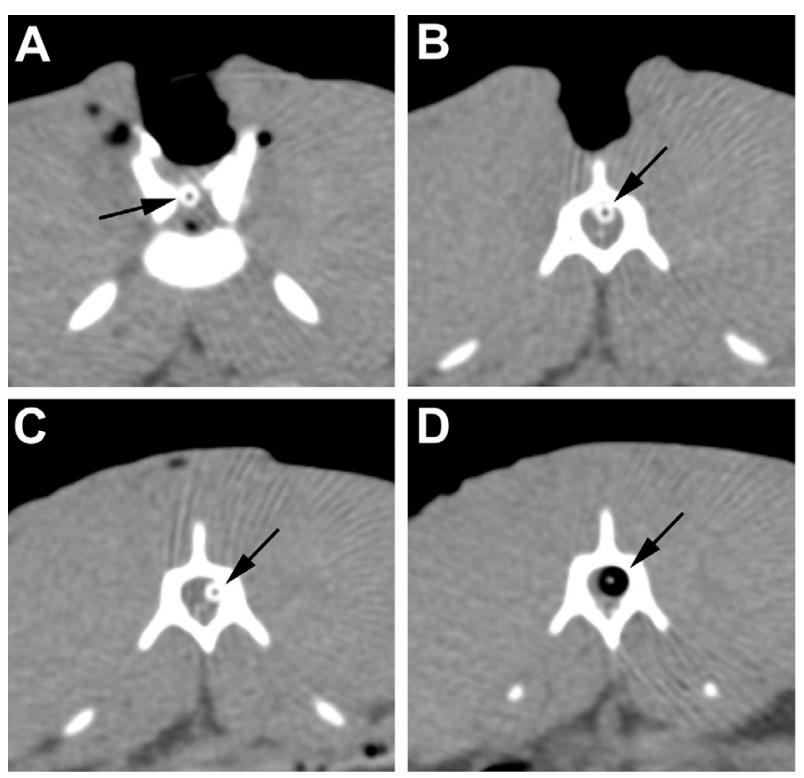

Figure 2 - CT images in the axial plane of a representative animal showing the catheter placed inside the spinal canal. (A) Image of the point of insertion of the catheter (arrow), in the L3 vertebra. ( $B$ and $\mathbf{C}$ ) Images showing the position of the catheter (arrows) inside the L2 (B) and L1 (C) vertebras. (D) Image showing the balloon inflated (arrow) inside the T13 vertebra. Note that the volume of the balloon inflated fills a significant part of the spinal canal space, promoting a large level of spinal cord compression.

\section{Obtainment of autologous BMMC}

Autologous BMMC were harvested aseptically from the femurs. In the animals treated $8 \mathrm{hr}$ after the $\mathrm{SCl}$, the extraction of the bone marrow was immediately made after the surgery. In the animals treated 7 days after the $\mathrm{SCl}$, the extraction was made after anesthesia with midazolam maleate $(3 \mathrm{mg} / \mathrm{kg}$ ) associated with the ketamine hydrochloride (25 mg/kg), administered intramuscularly. A trichotomy was made in the thigh and the puncture was made with a needle for pediatric use (gauge 18G). The following procedure was made as previously described ${ }^{27}$.
Briefly, the bone marrow was collected in sterile tubes with serum-free DMEM-F12 (GIBCO BRL, Grand Island, NY, USA). Cells were mechanically dissociated, centrifuged and resuspended in serum-free DMEM-F12. Separation of mononuclear fraction was done by centrifugation in Histopaque 1077 (SigmaAldrich, St. Louis, MO, USA). Mononuclear cells were collected, washed, counted and suspended in phosphate-buffered saline (PBS). The whole procedure lasted 5-6 hr.

\section{Obtainment of allogeneic MSC}

The culture for MSC was made as previously described ${ }^{27}$. The excess of BMMC obtained from the animals treated with BMMC 7 days after the $\mathrm{SCl}$ was plated in $75 \mathrm{~cm}^{2}$ flasks (a flask for each animal) with DMEM-F12 supplemented with $10 \%$ fetal bovine serum (FBS), a mix of antibiotics (50 $\mathrm{U} / \mathrm{ml}$ penicillin $\mathrm{G}, 50 \mathrm{\mu g} / \mathrm{ml}$ streptomycin, and $100 \mu \mathrm{g} / \mathrm{ml}$ neomycin; Sigma-Aldrich), and 2.5 $\mu \mathrm{g} / \mathrm{ml}$ amphotericin B (Sigma-Aldrich), and maintained at $37{ }^{\circ} \mathrm{C}$ in $5 \% \mathrm{CO}_{2}$. Nonadherent cells were partially removed by replacing the medium at intervals of 3-4 days. After reaching confluence, cells were harvested with $0.25 \%$ trypsin $+0.04 \%$ EDTA-4Na (GIBCO). The cells of each flask was replated on two new others. After the fourth replating and after reaching confluence, MSC were harvested, washed, counted and suspended in PBS.

\section{Experimental groups and transplantation}

The animals submitted to $\mathrm{SCl}$ were divided in the following experimental groups:

- Control: the animals received intravenous (iv) injection of the vehicle (1 $\mathrm{ml}$ of PBS) at $8 \mathrm{hr}$ and 7 days after the $\mathrm{SCl}$ $(n=8)$;

- BMMC-8h: the animals received iv injection of $3 \times 10^{7}$ autologous BMMC in 1 $\mathrm{ml}$ of PBS at $8 \mathrm{hr}$ after the $\mathrm{SCl}(\mathrm{n}=8)$; 
- $\quad$ BMMC-7d: the animals received iv injection of $3 \times 10^{7}$ autologous BMMC in $1 \mathrm{ml}$ of PBS at the post-injury day (PID) 7 $(n=6)$;

- MSC-8h: the animals received iv injection of $3 \times 10^{6}$ allogeneic MSC in $1 \mathrm{ml}$ of PBS at $8 \mathrm{hr}$ after the $\mathrm{SCl}(\mathrm{n}=6)$;

- MSC-7d: the animals received iv injection of $3 \times 10^{6}$ allogeneic MSC in $1 \mathrm{ml}$ of PBS at the PID $7(n=7)$.

All injections were made through the marginal vein of the left ear, in a nonstressful procedure without any anesthesia. No additional group with sham procedure for the $\mathrm{SCl}$ and bone marrow extraction was made for ethical reasons. The possible influence of the bone marrow extraction in the BMMC-7d group is discussed forward.

\section{Sensorimotor evaluation}

All experimental animals were submitted to a sensorimotor evaluation of the hindlimbs. As made in previous studies ${ }^{30,31}$, the evaluation was adapted from the score proposed by Tarlov and Klinger (1954), with the addition of the assessment of the presence or absence of pain withdraw. The sensorimotor score used is described in the Table 1. All animals had the score 4 before the $\mathrm{SCl}$ induction. After the $\mathrm{SCl}$ induction, only animals with score 0 were used in the experiment. For the postinjury evaluation, the animals that received the treatment $8 \mathrm{hr}$ after the $\mathrm{SCl}$ (including those of the control group) were filmed at the PIDs 7, 14, 21 and 28. The animals that were treated at the PID 7 were filmed at the PIDs 14, 21 and 28. Only animals that had score 0 at the PDI 7 were treated at this PID and considered for evaluation. The films lasted 4-5 $\mathrm{min}$, and they were analyzed and ranked by six blind observers, in accordance to the score of the Chart 1.
Chart 1 - Criteria of the sensorimotor scoring.

\begin{tabular}{ll}
\hline Score & Sensorimotor outcome \\
\hline 0 & $\begin{array}{l}\text { No voluntary movement or pain } \\
\text { withdrawal }\end{array}$ \\
1 & $\begin{array}{l}\text { Perceptible voluntary movement, absence } \\
\text { of pain withdrawal }\end{array}$ \\
2 & $\begin{array}{l}\text { Perceptibly voluntary movement, } \\
\text { presence of pain withdrawal }\end{array}$ \\
3 & $\begin{array}{l}\text { Good voluntary movement but inability to } \\
\text { stand, presence of pain withdrawal } \\
\text { Ability to stand and/or walk, presence of } \\
\text { pain withdrawal }\end{array}$ \\
\hline
\end{tabular}

Histology

All animals were euthanized 13 days after the treatment. The whole Central Nervous System was removed and fixed with $10 \%$ formalin. The brain and the cervical, thoracic, lumbar and sacral regions of the spinal cord were dissected and processed with the standard protocol for the hematoxylin and eosin (H\&E) staining.

\section{Data analysis}

For the statistical analysis of the sensorimotor evaluation, the value that was considered as the score for each film was the mean of the scores of the six blind observers. The analysis of the control, BMMC-8h and MSC-8h groups at the PID 7 was made by the one-way ANOVA, followed by Tukey posttest. After the PID 7, an animal of the control group and two animals of the BMMC-8h group died. Thus, the number of animals of the control and BMMC-8h groups changed to 7 and 6 in the subsequent PIDs, respectively. The analysis of these PIDs (14, 21 and 28) including all experimental groups was made by the repeated measures two-way ANOVA. The factors were "treatment" vs. "PID", and the last 
was the matched factor. Because a significant interaction among the factors was found, oneway ANOVA and Tukey post-test were made for each PID. The level of significance was always set at $p<0.05$.

For the histopathological analysis, the slices from the different regions of the spinal cord stained with H\&E were observed in a brightfield microscope with a digital camera connected to PC computer. Digital images were captured for illustration. A qualitative analysis was made, with the evaluation of the morphology of the neural cells and of the non-neural infiltrated cells, as well the general tissue pattern. The aim was to feature the type of lesion promoted by the spinal cord compression and to find possible gross differences among the experimental groups.

\section{Results}

The balloon compression model simulates compression of the spinal cord, which can be caused by a fracture dislocation of the spine, a herniated disc or a tumor. These pathological conditions are common and promote injury by mechanical and vascular causes ${ }^{28,29}$. The sensorimotor evaluation showed that our protocol of induction of $\mathrm{SCl}$ was able to promote a deep impairment of the spinal cord function, since a complete loss of the sensorimotor response (score 0) was observed in the first hr after the $\mathrm{SCl}$ in almost all experimental animals. The few animals that did not have this score were discarded from the study. At PID 7, both therapies given at $8 \mathrm{~h}$ after the $\mathrm{SCl}$ promoted the same level of recovery (Figure 3). At PID 14, only the BMMC-7d group promoted no significant recovery, since it was not different from the control group (Figure 3 ). In the PIDs 21 and 28, all treatments promoted significant recovery, since they differed from the control group and had no difference between them (Figure 3).

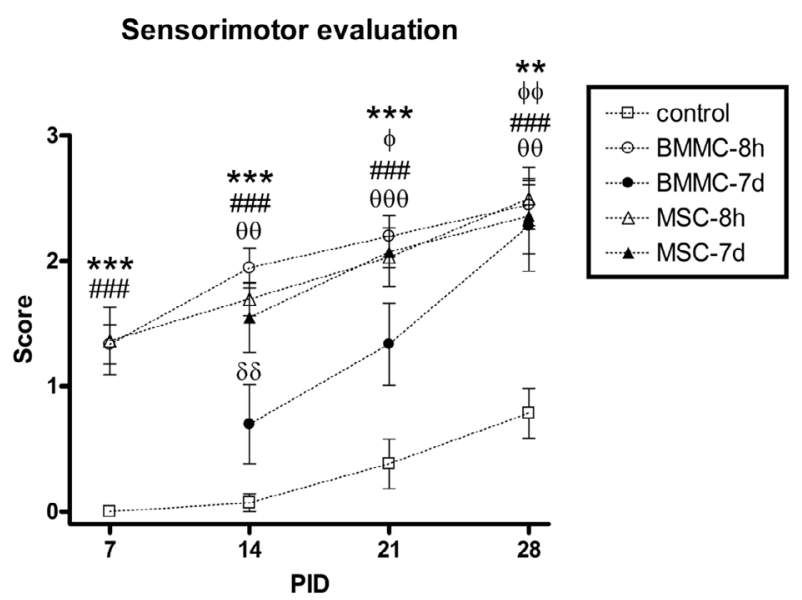

Figure 3 - Graph showing the results of the sensorimotor evaluation. At PID 7, a significant difference was found among groups $(F=24.08$, $p<0.001$; ANOVA). The BMMC-treated groups were significantly different from the control group, but they were not different. In the following PIDs, the analysis of all experimental groups against the time (PIDs) showed a significant interaction among these factors ( $\mathrm{F}=2.22, p<0.05$; two-way ANOVA). At PID 14 ( $F=11.22, p<0.001 ;$ ANOVA), all cell-treated groups differed from the control group, excepting the BMMC-7d group, which differed from the BMMC-8h group. At PIDs 21 ( $F=13.2, p<0.001$; ANOVA) and 28 ( $F=8.03, p<0.001$; ANOVA), all celltreated groups differed from the control group, but did not differ among themselves. *- comparison among BMMC-8h and control groups; $\phi$ comparison among BMMC-7d and control groups; \# - comparison among MSC-8h and control groups; $\theta$ - comparison among MSC-7d and control groups; $\delta$ - comparison among BMMC-8h and BMMC-7d groups. One symbol means $p<0.05$; two symbols mean $p<0.01$; three symbols mean $p<0.001$; Tukey. Squares, circles and triangle represent mean \pm SEM.

The histopathological analysis showed typical features of an ischemic lesion induced by compression (Figure 4). The tissue alterations were found only the site of lesion and in the segments posterior to it (lumbar and sacrum spinal cord regions). There was no difference in the intensity or quality of the lesion among the experimental groups, which makes it impossible to corroborate any significant effect of the treatments in the tissue alterations. 


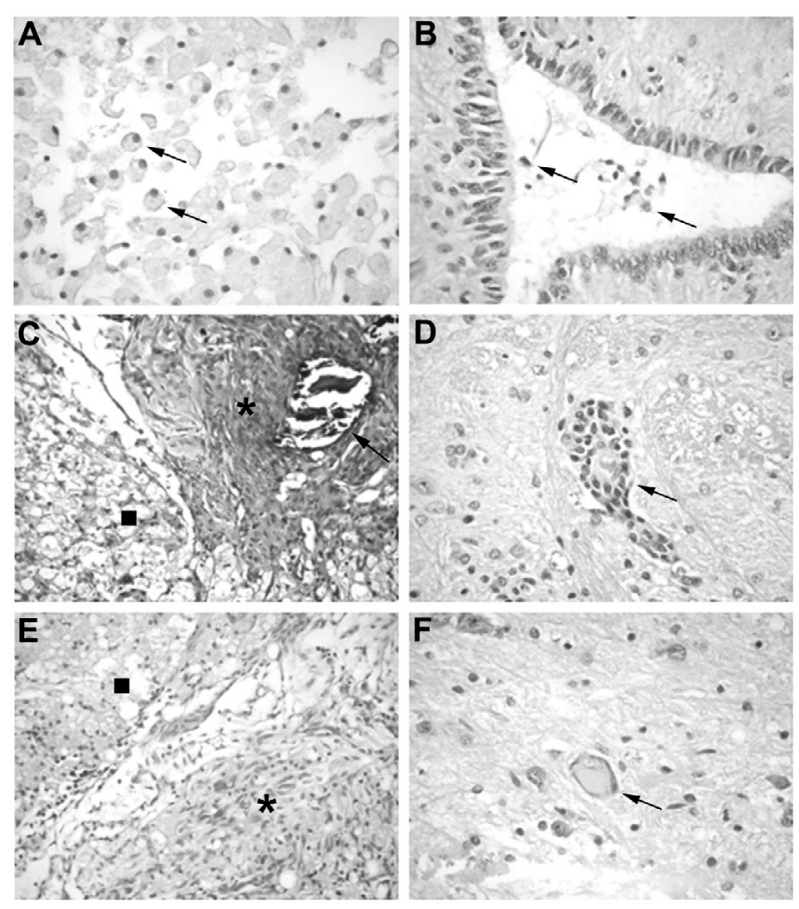

Figure 4 - Representative images of the spinal cord sections stained with $\mathrm{H} \& \mathrm{E}$, showing the general histopathological features that were observed. (A) Image of a section from a thoracic spinal cord segment located inside the T13 vertebra, showing numerous microglial phagocytic cells, typically performing phagocytosis of lipids from the myelin of the myelomalacia. Arrows point some of them. (B) Image of a section from a lumbar spinal cord segment showing macrophages inside the central canal, containing hemosiderin in their cytoplasm (two of them pointes by arrows). (C) Image of a section from a lumbar spinal cord segment showing the mineralization (arrow) of the markedly thickened meninges by fibrosis (asterisk) and numerous foamy macrophages (square). (D) Image of a section from a sacrum spinal cord segment showing mononuclear inflammatory (lymphocytes) infiltrate around a capillary (arrow). (E) Image of a section from a sacrum spinal cord segment showing a marked fibrosis of the meninges. Numerous fibroblasts permeated by moderate amount of collagenous matrix (asterisk) and numerous foamy macrophages (square) can be observed. (F) Image of a section from a lumbar spinal cord segment showing a typical degenerating neuron (arrow), with central chromatolysis and peripheral nucleus.

\section{- Discussion}

Bone marrow-derived cells have been consistently shown as good candidates to treat CNS lesions. The two main protocols that have been used in preclinical and clinical studies are those to use MSC and BMMC. However, few studies have compared their efficacy into a same experimental design, and they have suggested that these cell types have similar beneficial effects ${ }^{23,24,27}$. Regarding the $\mathrm{SCl}$, Urdzíková et al. ${ }^{23}$ evaluated the intravenous administration of bone marrow-derived MSC or BMMC a week after lesion in rats and showed that both cell types promoted positive effects on neurological recovery and histopathological process, but the MSC were slightly more effectives. Wright et al. ${ }^{7}$ evaluated the intralesional administration of human MSC or human BMMC at the time of lesion induction in rats immune suppressed with Cyclosporine, and showed that the treatments had very similar positive effects on inflammation, host immune response, grafting efficacy and glial scarring. Our results in rabbits are in agreement to these previous studies, because we showed that MCS and BMMC promoted significant sensorimotor recovery after $\mathrm{SCl}$ with the same level of efficacy. The only difference observed among treatments was at PID 14, since the group treated with BMMC at PID 7 showed no significant recovery. This result suggests that the treatment with $B M M C$ might be less effective to promote recovery when it is administrated a week after lesion induction than when it is administrated $8 \mathrm{hr}$ after lesion induction. However, another possible explanation to this result might be a deleterious effect of the bone marrow extraction to which the group treated with BMMC at PID 7 was submitted, including a second process of anesthesia. In fact, the treatment with BMMC at PID 7 was able to promote the same level of sensorimotor recovery observed in other treated groups in the subsequent survival 
times, and thus the treatment with BMMC at PID 7 had only a delay to reach the maximal level of recovery observed in this study.

Moreover, previous reports have shown the effectiveness of the treatment of $\mathrm{SCl}$ with bone marrow-derived or umbilical cord bloodderived cells, but using a single time window of administration of cells, including administration from $\mathrm{hr}$ to three days after $\mathrm{SCl}^{17,18,20}$ or a week after $\mathrm{SCl}^{23}$. In a phase I clinical trial, Syková et al. ${ }^{21}$ reported the administration of autologous BMMC in acute/sub acute (10-30 days after $\mathrm{SCl}$ ) and chronic (2-17 days after $\mathrm{SCl}$ ) patients, and showed outcomes mainly in the acute patients. In the present work we tested two different time windows of treatment with bone marrow-derived cells in an experimental model of $\mathrm{SCl}$ into a same experimental design. Our results suggest that the treatment made a week after $\mathrm{SCl}$ is as efficient to promote sensorimotor recovery as made at the day of the $\mathrm{SCl}$. This suggestion can have positive implications to the clinical use of this therapy, because the time window of a week between the occurrence of the spinal lesion and the hospital care for the administration of the cell therapy is more feasible than a time window of hours to few days after $\mathrm{SCl}$.

Other positive implication to the use of the bone-marrow-derived cells to treat the $\mathrm{SCl}$ is the possibility to use autologous BMMC instead of MSC, since the use of BMMC is a faster and cheaper protocol. Moreover, our results and previous reports have suggested that these two therapeutic protocols have the same effectiveness to promote recovery. Although MSC have shown a great therapeutic potential to be used in many different types of diseases, their achievement requires cell cultivation for weeks, endearing the process and impairing the autologous treatment in the acute phase of CNS injuries. Nevertheless, beside the risk of interpersonal transmission of pathogens in an allogeneic transplantation, recent reports have suggested that MSC are not hypoimmunogenic, but immuno evasive, since they can induce some level of immunologic response ${ }^{13}$.

According to our qualitative histopathological analysis of the injury, there was no difference between the groups, suggesting that the treatment did not promote significant change in histopathological process to be viewed by a more superficial analysis. However, we cannot say that more subtle changes have not been promoted by both types of treatment used. Thus, future studies using specific markers for cell types and components of the extracellular matrix are needed to clarify this issue.

\section{Conclusion}

The possibilities of therapy with bone marrow-derived cells and their time after injury to be administrated are large, increasing the therapeutic arsenal for the treatment of $\mathrm{SCl}$.

\section{References}

1. Singh A, Tetreault L, Kalsi-Ryan S, Nouri A, Fehlings MG. Global prevalence and incidence of traumatic spinal cord injury. Clin Epidemiol. 2014;6:309-31. doi: 10.2147/ CLEP.S68889.

2. Sherzai $A Z$, Elkind MS. Advances in stroke prevention. Ann N Y Acad Sci. 2015;1338:115. PMID: 25779474.

3. Wang J, Yang W, Xie H, Song Y, Li Y, Wang L. Ischemic stroke and repair: current trends in research and tissue engineering treatments. Regen Med Res. 2014;2:3. PMID: 25984331.

4. Young W. Spinal cord regeneration. Cell Transplant. 2014;23:573-611. doi: 10.3727/096368914X678427.

5. Furlan JC, Noonan V, Singh A, Fehlings MG. Assessment of impairment in patients with acute traumatic spinal cord injury: a systematic review of the literature. J Neurotrauma. 2011;28:1445-77. doi: 10.1089/neu.2009.1152. 
6. Mothe AJ, Tator $\mathrm{CH}$. Advances in stem cell therapy for spinal cord injury. J Clin Invest. 2012;122:3824-34. PMID: 23114605.

7. Wright KT, El Masri W, Osman A, Chowdhury J, Johnson WE. Concise review: bone marrow for the treatment of spinal cord injury: mechanisms and clinical applications. Stem Cells. 2011;29:169-78. doi: 10.1002/ STEM.570.

8. Enomoto $\mathrm{M}$. The future of bone marrow stromal cell transplantation for the treatment of spinal cord injury. Neural Regen Res. 2015;10:383-4. doi: 10.4103/16735374.153684.

9. Mezey E. Bone marrow-derived stem cells in neurological diseases: stones or masons? Regen Med. 2007;2:37-49. doi: 10.2217/17460751.2.1.37.

10.Maltman DJ, Hardy SA, Przyborski SA. Role of mesenchymal stem cells in neurogenesis and nervous system repair. Neurochem Int. 2011;59:347-56. doi: 10.1016/j. neuint.2011.06.008.

11.lihoshi S, Honmou O, Houkin K, Hashi $\mathrm{K}$, Kocsis JD. A therapeutic window for intravenous administration of autologous bone marrow after cerebral ischemia in adult rats. Brain Res. 2004;1007:1-9. doi: 10.1016/j.brainres.2003.09.084.

12.Ryan JM, Barry FP, Murphy JM, Mahon BP. Mesenchymal stem cells avoid allogeneic rejection. J Inflamm. 2005;2:8. doi: 10.1186/1476-9255-2-8.

13.Griffin MD, RitterT, Mahon BP.Immunological aspects of allogeneic mesenchymal stem cell therapies. Hum Gene Ther. 2010;21:164155. doi: 10.1089/hum.2010.156.

14.Weissman IL, Anderson DJ, Gage F. Stem and progenitor cells: origins, phenotypes, lineage commitments, and transdifferentiations. Rev Cell Dev Biol. 2001;17:387-403. doi: 10.1146/annurev.cellbio.17.1.387.

15.Pittenger MF, Mackay AM, Beck SC, Jaiswal RK, Douglas R, Mosca JD, Moorman MA, Simonetti DW, Craig S, Marshak DR. Multilineage potential of adult human mesenchymal stem cells. Science. 1999;284:143-7. PMID: 10102814.

16.Takahashi M, Li TS, Suzuki R, Kobayashi T, Ito $\mathrm{H}$, Ikeda $\mathrm{Y}$, Matsuzaki M, Hamano, K. Cytokines produced by bone marrow cells can contribute to functional improvement of the infarcted heart by protecting cardiomyocytes from ischemic injury. Am J Physiol Heart Circ Physiol. 2006;291:886-93. doi: 10.1152/ajpheart.00142.2006.

17. Akiyama Y, Radtke C, Honmou O, Kocsis JD. Remyelination of the spinal cord following intravenous delivery of bone marrow cells. Glia. 2002;39:229-36. doi: 10.1002/ glia.10102.

18. Yoshihara T. Neuroprotective effect of bone marrow-derived mononuclear cells promoting functional recovery from spinal cord injury. J Neurotrauma. 2007;24:102636. doi: 10.1089/neu.2007.132R.

19.Giraldi-Guimarães A, Rezende-Lima $M$, Bruno FP, Mendez-Otero R. Treatment with bone marrow mononuclear cells induces functional recovery and decreases neurodegeneration after sensorimotor cortical ischemia in rats. Brain Res. 2009;1266:108-20. PMID: 19368806.

20.Sampaio MFS, Marcilio FS, GiraldiGuimarães A. Does treatment with bone marrow mononuclear cells recover skilled motor function after focal cortical ischemia? Analysis with a forelimb skilled motor task in rats. Brain Res. 2013;1492:130-9. doi: 10.1016/j.brainres.2012.11.026.

21.Syková E. Autologous bone marrow transplantation in patients with subacute and chronic spinal cord injury. Cell Transplant. 2006;15:675-87. PMID: 17269439.

22.Aghayan HR, Arjmand $B$, Yaghoubi $M$, Moradi-Lakeh M, Kashani $H$, Shokraneh F. Clinical outcome of autologous mononuclear cells transplantation for spinal cord injury: a systematic review and meta-analysis. Med J Islam Repub Iran. 2014;28:112. PMID: 25678991.

23.Urdzíková $L$, Jendelová $P$, Glogarová K, Burian M, HájekM, Syková E. Transplantation of bone marrow stem cells as well as mobilization by granulocyte-colony stimulating factor promotes recovery after spinal cord injury in rats. J Neurotrauma. 2006;23:1379-91. doi: 10.1089/neu.2006.23.1379.

24.Pastor D, Viso-León MC, Jones J, JaramilloMerchán J, Toledo-Aral JJ, Moraleda JM, Martínez S. Comparative effects between bone marrow and mesenchymal stem cell transplantation in GDNF expression and motor function recovery in a motorneuron degenerative mouse model. Stem Cell Rev. 2012;8:445-58. doi: 10.1007/s12015-011-9295-x. 
25.Shen LH. Therapeutic benefit of bone marrow stromal cells administered 1 month after stroke. J Cereb Blood Flow Metab. 2007;27:6-13. doi: 10.1038/ sj.jcbfm. 9600311 .

26.Komatsu K, Honmou O, Suzuki J, Houkin $\mathrm{K}$, Hamada $\mathrm{H}$, Kocsis JD. Therapeutic time window of mesenchymal stem cells derived from bone marrow after cerebral ischemia. Brain Res. 2010;1334:84-92. doi: 10.1016/j. brainres.2010.04.006.

27.De Vasconcelos AS, Da Costa JR, Diaz BP, Moraes L, Giraldi-Guimarães A, Mendez-Otero R. Therapeutic window for treatment of cortical ischemia with bone marrow-derived cells in rats. Brain Res. 2010;1306:149-58. PMID: 19853605.

28.Tarlov, I. M., Klinger, H. and Vitale, S. Spinal cord compression studies. I. Experimental techniques to produce acute and gradual compression. AMA Arch Neurol Psychiatry. 1953;70:813-9. PMID: 13103865.

29.Vanický I, Urdzíková L, Saganová K, Cízková D, Gálik J. A simple and reproducible model of spinal cord injury induced by epidural balloon inflation in the rat. J Neurotrauma. 2001;18:1399-407. doi:

\subsection{9/08977150152725687.}

30. Kerasidis H, Wrathall JR, Gale K. Behavioral assessment of functional deficit in rats with contusive spinal cord injury. J Neurosci Methods. 1987;20:167-79. PMID: 3600032.

31. Noble LJ, Wrathall JR. Correlative analyses of lesion development and functional status after graded spinal cord contusive injuries in the rat. Exp Neurol. 1989;103:34-40. PMID: 2912748.

32. Tarlov IM, Klinger H. Spinal cord compression studies. II. Time limits for recovery after acute compression in dogs. AMA Arch Neurol Psychiatry. 1954;71:271-90. PMID: 13123590.

\section{Acknowledgements}

To Lorrana Abud Licassali, Tomas Ottoni Barroso da Silva, Matheus Roberto da Mota Costa, Guilherme de Souza Viera, Leonardo Waldstein, and Priscila Helena Anibaleti Machado for attending as blind observers of the films for the sensorimotor evaluation.

\section{Correspondence:}

André Lacerda de Abreu Oliveira Laboratório de Sanidade Animal, Centro de Ciências e Tecnologias Agropecuárias Unidade de Experimentação Animal, UENF Avenida Alberto Lamego, 2000 28013-602 Campos dos Goytacazes - RJ Brasil Tel.: (55 21)2748-6084 / 99397-0795 andrevet@uol.com.br

Received: Aug 17, 2017

Review: Oct 18, 2017

Accepted: Nov 16, 2017
Conflict of interest: none

Financial sources: CNPq, FAPERJ

\begin{abstract}
${ }^{1}$ Research performed at Laboratory of Animal Health, Center for Agricultural Sciences and Technologies, Animal Experimentation Unit, Universidade Estadual do Norte Fluminense Darcy Ribeiro (UENF), Campos dos GoytacazesRJ, Brazil.
\end{abstract}

